\title{
A Study of Elders' Health Status and Perception about Old Age
}

\section{Keshab Prasad Timalsina}

Lecturer, Makawanpur Multiple Campus,

Email: timalsina.keshab73234@gmail.com

DOI: https://doi.org/ 10.3126/irjmmc.v2i4.41554

Received: December 11, 2021; Revised \& Accepted: December 19, 2021; Published: December 22, 2021

(C) Copyright: Timalsina (2021).

\section{ABSTRACT}

The health status of elders and elders' perception regarding old age in a community is an important issue in a society. The present study aims to assess the health status and perception of old age of elderly population of Nijgadh Municipality. A descriptive crosssectional study has been carried out among 204 elders taken from the community through simple random sampling method. The data were collected through face to face structured interview schedule in 2021. The descriptive and inferential statistical analysis of the collected data showed that the about 20 percent elders had got good status of health but remaining (about $80 \%$ ) of them were suffering from some kinds of health complications. Similarly, more than 73 percent of elders felt their life more problematic. This study measured significant variation $(p<0.05)$ of level of health status with only three socio-demographic variables (age, caste, and feeling of helplessness among the variables (gender, age groups, caste, living with or without spouse, literacy status, and feeling helplessness. Furthermore, this study measured significant variation $(p<0.05)$ of perception about old age of elderly population with only three socio-demographic variable (age, caste, and feeling of helpless) among the variables (gender, age groups, caste, living with or without spouse, literacy status, and feeling helplessness). Based on the study, it can be said that age, caste, and feeling of helplessness status of elderly population were the major factors for creating variations in health status and perceptions of elderly life. The policies, programs, and community effort are needed for managing regular health service practice. Similarly, all the community members must be serious for keeping elders happy by managing their requirement with love which may require collective action from social, health and justice sectors.

Keywords: Aging, feeling of safety, health check-up, health status, perception about old age

\section{INTRODUCTION}

Aging is a normal process that happens to everyone at some point in their lives. The term "aging" refers to the process of becoming older along with the effects of growing older resulted in a loss in physiological. Physical changes such as wrinkled skin, gray hairs, loose teeth, walking with a stick and bending-back, and hearing and vision loss are all signs that a person is getting older biologically (Timalsina, 2021). Various changes connected to aging occur during a person's lifetime, affecting his ability to function in his surroundings. A person does not simply get old; it is a long process that is influenced by factors like heredity, diet, 
mental attitude, environment, and level of life, among others. For biomedical purposes, aging is divided into three generations depending on physical and physiological capacity: early elderly (60-73 years), middle aged elderly (74-84 years), and late elderly (85+ years) (Wallace, 1977).

The elderly population in Nepal is defined as those who are 60 years old or older. However, the average retirement age for government employees is 58 years old (CBS, 2014), but this study is primarily focused on persons aged 60 and up.

Nepal is transitioning from a rural to an urban society. In our culture, extended or joint families were common, and old people were regarded as the family's eye person with a vision. Old people are currently being separated and ignored in their families as a result of the influences of modernity and rising nuclear family notions. As a result, the social and physical well-being of the elderly is jeopardized. They are either purposely isolated from their families or are separated for self-interest and live a lonely existence (NHRC, 2009).

Family and household structures have evolved as a result of urbanization and changes in demographic composition, with an average family size of 4.6 in 2011 compared to 4.88 in 2001 and 5.6 in 1991. In Nepal, those aged 60 and up are referred to be elderly, and the ageing index has risen from $7.79 \%$ in 1971 to $10.92 \%$ in 2001 and 15.50 in 2011 . The percentage of people aged 60 and more increased from 7.46 percent in 2001 to 8.1 percent in 2011. The yearly older population growth rate was 3.39 percent from 1991 to 2001, which was higher than the annual population growth rate of 2.1 percent. And annual growth rate of population 60 year and more was observed 3.07 between the period 1981 to 2011(CBS, 2014).

Nepal's population is in the midst of a transformational period. According to the 2011 census report, more than 55 percent of the current population is of working age, ranging from 15 to 59 years old, indicating the country's potential for rapid development. On the other hand, there are 2.1 million elders in the country, accounting for 8.1 percent of the overall population and the dependent population. Similarly, this population is considered vulnerable and suffers from the long-term effects of deprivation, including poor health and nutrition, low social status, discrimination and mobility restrictions, and a lack of resources to meet basic needs such as food, clothing, shelter, health care, love, and affection (Timalsina, 2021).

Because the elderly population is growing at a faster rate than the general population, the number of elderly people in our country is growing. The yearly elderly population growth rate is 3.07 percent (CBS, 2014), which is greater than the general population growth rate. Similarly, our family structure is changing from extended or joint to nuclear family, therefore these old people are either avoided by their families or left alone in their homes. Older individuals are experiencing a variety of social and health issues as a result of these situations.

"Aging is an inevitable mutual separation or disengagement, resulting in decreasing connection between the older patient and others in the social system to which he belongs," according to the disengagement hypothesis of ageing (Coleman, 1991, p219). Older people withdrawing from society are natural and appropriate, according to this viewpoint (Ebersole $\&$ Ebersole, 2005). Moral disengagement theory is one of the many types of disengagement theories (Bandura, 2016) In the field of geriatrics, it's crucial. Since it was first offered as innate, universal, and unidirectional, the concept has gotten a lot of flak (Achenbaum, 1995). 
According to the disengagement theory, people withdraw from personal relationships and society as they get older (Bengtson, 2009).

Province 2 of Nepal is considered a comparatively deprived province of Nepal in terms of development, education, national services, and other facilities. People are forced to live in low-quality environments due to weak socio-cultural environments and opportunities, as seen by the low HDI rating (HDI=0.510) (UNDP, 2019). In such a case, it is vital to comprehend the predicament of the elderly. As a result, this study analyses the social and health situation of the senior population in the Terai-Bhawar regions using representative survey respondents from the Terai-Bhawar regions.

\section{OBJECTIVE}

- To assess the health status and perception of old age among the elders.

\section{HYPOTHESIS OF THE STUDY}

- There is a statistical variation of mean rank of health status by socio-demographic characteristics of elderly people.

- There is a statistical variation of mean rank of perception about elder's life by sociodemographic characteristics of elderly people.

\section{METHODS AND MATERIALS}

From July to August 2021, a descriptive, community based, cross-sectional study was conducted in Nijgadh Municipality. In total, 538 elders from three wards of Nijgadh municipality were listed in the voter list (NEC, 2018), and this number was used as the study's universe. Simple random sampling was used to choose 3 wards among the nine wards of the municipality. Yamane's (1967) formula was used to determine the study's sample size: $n=\frac{N}{1+\left(N \times(0.05)^{2}\right.}$. By conducting a pilot study, the sample size was estimated, and a total of 229 people were chosen using a simple random sampling procedure among 538 old age population. The researchers trained enumerators to interview a total of 229 subjects using pre-tested questionnaire. The interview was conducted in the Nepali language. Finally, data collection for 204 senior people was successfully accomplished out of 229 samples. 12 of the 25 older people who were not included in the study denied to respond, 2 had incomplete interviews, and 11 were not found when the data was collected. The goal of the study was described to the participants, and oral informed consent was obtained. The privacy and secrecy of the interview as part of the study were also taken into consideration. Each respondent was questioned individually where they felt comfortable, to avoid intervention and influence from other family members and neighbours. The data was tabulated and analyzed using the statistical tool SPSS, Version 26 for Windows. The findings were described using descriptive and inferential statistics.

\section{RESULTS}

\section{a. Socio-Demographic Characteristics of Older Population}

The socio-demographic characteristics of the elderly are shown in Table 1. In terms of gender, females account for 52.00 percent $(\mathrm{N}=106)$ of the old population, while males account for 48.00 percent $(\mathrm{N}=98)$. Similarly, the study considered aging to be a significant 
characteristic of the elderly. The study divides people into four age groups. The bulk of senior adults were discovered in the 60-64 year age bracket, according to age. In the age group 60-64 years, more than a quarter $(27.9 \% ; \mathrm{N}=57)$ of old adults were found. The second-largest elderly population was found in the age group 75 and above, which accounts for around 24.00 percent $(\mathrm{N}=52)$ of the total population. The old population in the age categories $70-74$ years was found to be the smallest of the four, accounting for slightly more than one-fifth $(22.5$ percent; \& $\mathrm{N}=46$ ) of the total elderly population.

Table 1 Socio-demographic characteristics of elderly population

\begin{tabular}{llll}
\hline Social characteristics & Responses & Count & Percentage \\
\hline Gender & Male & 98 & $48.0 \%$ \\
& Female & 106 & $52.0 \%$ \\
Age Group & $60-64$ & 57 & $27.9 \%$ \\
& $65-69$ & 49 & $24.0 \%$ \\
& $70-74$ & 46 & $22.5 \%$ \\
Caste & $75+$ & 52 & $25.5 \%$ \\
& Brahmin & 36 & $17.6 \%$ \\
& Chhetri & 78 & $38.2 \%$ \\
Literacy Status & Dalit & 10 & $4.9 \%$ \\
\multirow{2}{*}{ Living } & Tamang & 50 & $24.5 \%$ \\
without & Tharu & 30 & $14.7 \%$ \\
Spouse & Literate & 87 & $42.6 \%$ \\
& Illiterate & 117 & $57.4 \%$ \\
Feeling Helpless & With & 141 & $69.1 \%$ \\
& & 63 & $30.9 \%$ \\
\hline
\end{tabular}

$\mathrm{N}=204$

Similarly, the senior population was divided into two groups based on their spousal living situation. The older persons who were living with a spouse at the time of the study are categorized as 'with spouse,' while those who were not living with a spouse are categorized as 'without spouse.' According to the report, there are a lot of older people who live with their spouses. Nearly two-thirds of the elderly population (64.89 percent, $\mathrm{N}=224)$ fell into the category of living with a spouse, while the remaining third (35.11 percent, $\mathrm{N}=132$ ) fell into the category of not living with a spouse. Similarly, according to caste/ethnicity, the Chhetri have the biggest elderly population (38.2\%), followed by Tamang (24.5\%), Brahmin (17.6\%), Tharu (14.7\%), and Dalit (4.9 percent).

According to literacy status, the bulk of the senior population was found to be illiterate, accounting for 57.4 percent $(\mathrm{N}=117)$, with the remaining 42.6 percent $(\mathrm{N}=87)$ belonging to the literate group. Similarly, the living situation of older people's spouses is a research variable. The bulk of the elderly population lived with their spouses, according to the research. More than two-thirds of the old population $(69.1 \%, \mathrm{~N}=141)$ lived with a spouse, with the remaining elderly people (30.9 percent, $\mathrm{N}=63$ ) living alone. Furthermore, the feeling of helplessness was a significant factor considered in the study, with data revealing that more than seven out of ten elders ( 72.5 percent \& $\mathrm{N}=148)$ reported 
feeling helpless occasionally, and an equal proportion of elders ( 28 percent vs 28 percent) reported feeling helpless not at all vs often. This study discovered the greatest number of elders with some disability ( 72 percent, $\mathrm{N}=182$ ).

\section{b. Health status of elders and perception regarding old age}

The information in the table above depicts the frequency and percentage distribution of elderly persons based on their health status. The health status of the elderly is the focus of this paper. According to the data above, the majority of older people fall into the category of having a fair health level. It accounted for over two-thirds of the population $(69.6 \%, \mathrm{~N}=142)$. The senior people with good health status $(\mathrm{N}=40)$ and poor health status $(\mathrm{N}=22)$ were determined to be $19.6 \%(\mathrm{~N}=40)$ and $10.8 \%$ (22) respectively. Similarly, this study was undertaken to learn about the perceptions of elder life among the study population, and it was discovered that the majority of respondents $(73.0 \%, \mathrm{~N}=149)$ saw elder life as problematic, and just a small percentage of elders $(5.9 \%, \mathrm{~N}=12)$ saw their lives as easy.

Table 2 Health status of elders and perception regarding old age

\begin{tabular}{llll}
\hline Area of Information & Responses & Count & Frequency \\
\hline Level of Health Status & Poor & 22 & $10.8 \%$ \\
& Fair & 142 & $69.6 \%$ \\
& Good & 40 & $19.6 \%$ \\
Perception about Elder & Easy & 12 & $5.9 \%$ \\
Life & Normal & 43 & $21.1 \%$ \\
& Problematic & 149 & $73.0 \%$ \\
\hline
\end{tabular}

$\mathrm{N}=204$

c. Variation of level of health status by socio-demographic characteristics

Table 3 shows that the mean rank of health status level was determined to be statistically significant in relation to age. The p-value 0.000 (at a $5 \%$ significance level) was less than 0.05 , indicating that there is a significant difference in the mean rank of elders' health status levels across age groups. According to the findings of this study, the average rank of elders' health status differed depending on their age group. Similarly, the data revealed that the gender of elders had no statistically significant effect on the mean rank of health status level. The p-value was 0.874 (at a $5 \%$ significance level), which is larger than 0.05 , indicating that there is no significant difference in the mean rank of health status level.

Table 3 Variation of level of health status by socio-demographic characteristics

\begin{tabular}{llllll}
\hline Characteristics & & $\mathrm{N}$ & $\begin{array}{l}\text { Mean } \\
\text { Rank }\end{array}$ & $\begin{array}{l}\mathrm{p}- \\
\text { Value }\end{array}$ & $\begin{array}{l}\text { Statistical } \\
\text { Value }\end{array}$ \\
\hline Gender & Male & 98 & 103.05 & 0.874 & $5140.000^{*}$ \\
& Female & 106 & 101.99 & & \\
Age Group & $60-64$ & 57 & 100.20 & 0.000 & $18.550^{* *}$ \\
& $65-69$ & 49 & 127.11 & & \\
& $70-74$ & 46 & 89.13 & & \\
Caste & $75+$ & 52 & 93.65 & & \\
& Brahmin & 36 & 108.67 & 0.048 & $9.874^{* *}$ \\
& Chhetri & 78 & 96.99 & & \\
Literacy Status & Dalit & 10 & 77.10 & & \\
& Tamang & 50 & 116.78 & 0.077 & \\
& Tharu & 30 & 94.10 & & \\
& Literate & 87 & 102.80 & 0.939 & $5056.50^{*}$ \\
& Illiterate & 117 & 102.28 & & \\
\hline
\end{tabular}




\begin{tabular}{llllll}
\hline Living with and & With & 141 & 104.46 & 0.379 & $4164.500^{*}$ \\
without Spouse & Without & 63 & 98.10 & & \\
Feeling Helpless & Not at all & 28 & 113.64 & 0.000 & $15.212^{* *}$ \\
& Sometimes & 148 & 106.47 & & \\
& Often & 28 & 70.39 & & \\
\hline
\end{tabular}

*Mann-Whitney U Test \&** Kruskal Wallis Test at 95\% CL

Table 3 shows that the mean rank of health status level was determined to be statistically significant in relation to age. The p-value 0.000 (at a 5\% significance level) was less than 0.05 , indicating that there is a significant difference in the mean rank of elders' health status levels across age groups. According to the findings of this study, the average rank of elders' health status differed depending on their age group. Similarly, the data revealed that the gender of elders had no statistically significant effect on the mean rank of health status level. The p-value was 0.874 (at a 5\% significance level), which is larger than 0.05 , indicating that there is no significant difference in the mean rank of health status level between male and female elders. It may be stated that the mean rank of health status level did not differ between men and women in the elderly population.

Furthermore, the data in table 3 shows that the mean rank of elders' health condition level was found to be statistically significant in relation to the elderly population's caste. The study discovered a p-value of $0.048(0.05)$, indicating that there is a significant variation in the mean rank of elderly population's health status level by caste of elders. It shows that the mean rank of elders' health status levels in the study differs significantly by caste of elders.

Similarly, Table 3 shows that the spousal living status had no statistically significant effect on the mean rank of times of elderly abuse. The p-value (at a 5\% significance level) was found to be 0.379 , which is greater than 0.05 . This means that there is no significant variation in the mean rank of elders' health status levels based on whether they live with or without a spouse. According to the findings, the mean rank of elders' health status level did not differ depending on whether they lived with or without a spouse.

Table 3 shows that the mean rank of elders' health status was determined to be statistically insignificant in relation to their literacy status. The p-value was 0.939 (at a $5 \%$ significance level), which is greater than 0.05 , meaning that there is no significant difference in the mean rank of elders' health status levels based on their literacy or illiteracy status. It may be inferred that the average rank of elders' health status did not differ considerably depending on their reading level.

Similarly, the data demonstrates that the mean rank of elders' health status level was statistically significant with the status of elders feeling helpless. The study discovered a significant difference in the mean rank of health status level of elders among three levels of helplessness status, with a p-value of 0.000 (at a 5\% significance level), which is less than 0.05. It can be established that the mean rank of elders' health status fluctuated depending on the elderly population's helplessness.

\section{d. Variation of elder's perception about old age}

Table 4 shows that the mean rank of perception about old age was determined to be statistically significant in relation to age, caste, and feeling of helpless but study did not observe the significant variation of the mean rank of perception about old age by gender, 
literacy status and living with and without spouse. The p-value 0.000 (at a 5\% significance level) was less than 0.05 , indicating that there is a significant difference in the mean rank of perception about old age across age groups. Furthermore, the study discovered a p-value of $0.002(0.05)$, indicating that there is a significant variation in the mean rank of perception about old age by caste of elders. It shows that the mean rank of perception about old age in the study differs significantly by caste of elders.

Similarly, the data demonstrates that the mean rank of perception about old age was statistically significant with the level of feeling helpless among elders. The study discovered a significant difference in the mean rank of perception about old age among three levels of helplessness status, with a p-value of 0.000 (at a 5\% significance level), which is less than 0.05 . It can be established that the mean rank of perception about old age fluctuated depending on the level of helplessness feeling.

Table 4 Variation of perception about old age by socio-demographic characteristics

\begin{tabular}{llllll}
\hline Characteristics & & Count & Mean Rank & $\begin{array}{l}\text { p- } \\
\text { Value }\end{array}$ & $\begin{array}{l}\text { Statistical } \\
\text { Value }\end{array}$ \\
\hline Gender & Male & 98 & 103.05 & 0.874 & $5140.000^{*}$ \\
& Female & 106 & 101.99 & & \\
Age Group & $60-64$ & 57 & 100.20 & 0.000 & $18.550^{* *}$ \\
& $65-69$ & 49 & 127.11 & & \\
& $70-74$ & 46 & 89.13 & & \\
Caste & $75+$ & 52 & 93.65 & & \\
& Brahmin & 36 & 74.75 & 0.002 & $17.146^{* *}$ \\
& Chhetri & 78 & 110.83 & & \\
Literacy Status & Tamang & 10 & 110.80 & & \\
& Dalit & 50 & 102.84 & & \\
Living with and & Tharu & 30 & 110.80 & & \\
without Spouse & Literate & 87 & 102.80 & 0.939 & $5056.50^{*}$ \\
Feeling Helpless & Illiterate & 117 & 102.28 & & \\
& With & 141 & 104.46 & 0.379 & $4164.500^{*}$ \\
& Without & 63 & 98.10 & & \\
& Not at all & 8 & 130.00 & 0.040 & $6.419^{* *}$ \\
& Sometimes & 182 & 99.70 & & \\
\hline
\end{tabular}

*Mann-Whitney U Test \&** Kruskal Wallis Test at 95\% CL

Table 4 shows that the mean rank of perception about old age was determined to be statistically significant in relation to age, caste, and feeling of helpless but study did not observe the significant variation of the mean rank of perception about old age by gender, literacy status and living with and without spouse. The p-value 0.000 (at a $5 \%$ significance level) was less than 0.05 , indicating that there is a significant difference in the mean rank of perception about old age across age groups. Furthermore, the study discovered a p-value of $0.002(0.05)$, indicating that there is a significant variation in the mean rank of perception about old age by caste of elders. It shows that the mean rank of perception about old age in the study differs significantly by caste of elders. 
Similarly, the data demonstrates that the mean rank of perception about old age was statistically significant with the level of feeling helpless among elders. The study discovered a significant difference in the mean rank of perception about old age among three levels of helplessness status, with a p-value of 0.000 (at a 5\% significance level), which is less than 0.05 . It can be established that the mean rank of perception about old age fluctuated depending on the level of helplessness feeling.

e. Safety feeling, place of treatment and trend of health check-up during old Age Table 5 distribution of elders by safety feeling, place of treatment and health check-up status

\begin{tabular}{llll}
\hline Area of information & Response & Count & Percentage \\
\hline Feeling safety with & Yes & 110 & $53.9 \%$ \\
Surrounding & No & 94 & $46.1 \%$ \\
Place of taking & Hospital & 123 & $60.3 \%$ \\
Treatment & Traditional Healer & 55 & $27.0 \%$ \\
& Baidhe & 26 & $12.7 \%$ \\
Practicing regular & Yes & 110 & $53.9 \%$ \\
Health check-up & No & 94 & $46.1 \%$ \\
\hline $\mathrm{N}=204$ & &
\end{tabular}

The data presented in table 5 shows that about 53.9 percent of respondents said they felt safe in their surroundings, while 46.1 percent said they don't. Respondents were asked to name the location where they generally go when they are sick and need medical help. About 60.3 percent of respondents said they go to a health centre, while another $27 \%$ said they go to a traditional healer. About 11 percent said they don't go anywhere for treatment, and about 12.7 percent said they go to Baidhaya. When asked if they had a regular health check-up, 53.9 percent said no, while 46.1 percent said yes.

\section{DISCUSSION}

The elderly stage is a natural occurrence in every human being's life cycle, however how the old stage is perceived, as well as their status, role, and obligations, varies depending on location and civilization. The transition from middle to elderly stage is a gradual one. People are considered elderly in many parts of the world when their activities or social roles change, such as when they become grandparents, or when they become less productive, or when they retire (NHRC, 2009).

This was a cross-sectional community-based study in Nijgadh municipality, which represents the Tarai Bhawar region of province 2, and it comprised primarily quantitative data. The goal of this study is to determine the health state of the older population as well as their attitudes toward old age. According to the study's findings, the health status of $69.6 \%$ of respondents was found to be fair, while $10.8 \%$ of the older population was found to be in poor health. Similarly, more than seven out of ten elders reported that they perceive their old age to be a problem. After evaluating numerous literatures on elder's health, this study used inferential analysis to evaluate the statistical variation in mean rank of level of health status across socio-demographic characteristics. Inferential statistics reveal that the mean rank of level of health status in the study area varies significantly by age group of elders $(p<0.05)$.

Similarly, the study discovered that the mean rank of health status differs considerably depending on the elders' caste $(p<0.05)$, and feeling of helpless $(p<0.05)$, but it was no 
significant variation with the remaining socio-demographic characteristics $(\mathrm{p}>0.05)$. As a result, the study accepted the hypothesis about the mean rank health status varies greatly depending on age, caste, and feeling of helplessness status of elderly population. Similarly, this study also found the significant variation in average perception of old age in the study area by age group $(\mathrm{p}<0.05)$ of elders. Similarly, the study discovered that the average perception of old age differs considerably depending on the elders' caste $(p<0.05)$, and feeling of helpless $(p<0.05)$, but it was no significant variation with the remaining socio-demographic characteristics $(p>0.05)$. Nearly half of the respondents said they felt not safe in their surroundings. About three in five of respondents said they go to hospital for treatment, while more than one forth said they go to a traditional healer. Nearly half of the elderly population was not practising regular health check-up services informs that there is still high chance of occurring health complication during the elder age.

\section{CONCLUSIONS}

Our community's elders have a higher incidence of health difficulties, and most of them are taking their life more difficult than normal. The community or the state should provide good management of frequent health check-ups for the elderly, reducing morbidity and further deterioration of pre-existing illnesses, and allowing them to live a better life. Similarly, every member of the community must be committed to making the lives of the elderly in their community safer, as well as to perceiving their lives as normal. Based on numerous socio-demographic characteristics, this study has produced data on the significant variation in level of health status and perceptions of old age, which can be utilized to identify and protect elders who are at high risk through multi-sectoral social justice action.

\section{RECOMMENDATIONS}

It is critical to do a micro-level study on resource allocation patterns at the household level and their consequences for older people's health and well-being in diverse geographies and socioeconomic circumstances. It is also necessary to examine the social, economic, and environmental aspects that influence overall health.

\section{ACKNOWLEDGEMENTS}

I admire all of the contributors in this study's cooperation.

\section{REFERENCES}

Achenbaum, W. A. (1995). Crossing frontiers: Gerontology emerges as a science. Cambridge University Press. https://doi.org/10.1017/CB09780511666803

Bandura, A. (2016). Moral disengagement: How people do harm and live with themselves. Worth Publishers, Macmillan Learning.

Bengtson, V. L. (Ed.). (2009). Handbook of theories of aging (2nd ed.). Springer.

Central Bureau of Statistics (CBS). (2014). Population monograph of Nepal. Kathmandu: CBS.

Coleman, P. (1991). Cumming E. and Henry W., Growing Old: The Process of Disengagement. Basic Books, New York, 1961. (Reprint: Arno, New York, 1979, ISBN 0405 118147.). Ageing and Society, 11(2), 217 220. https://doi.org/10.1017/S0144686X00004025 
Ebersole, P., \& Ebersole, P. (Eds.). (2005). Gerontological nursing \& healthy aging (2nd ed.). Elsevier Mosby.

National Election Commission (NEC). (2018). Voter list. Bara: NEC

Nepal Health Research Council (NHRC). (2009). Social and Health Status of Elderly Population in Far-Western Region. Kathmandu: NHRC.

Timalsina, K.P. (2021). Prevalence and Factors Influencing Elderly Abuse: A Descriptive Study of Jureli Village, Bakaiya. International Research Journal of MMC (IRJMMC), 2 (2), 38-49. http://surl.li/ayogxWallace, D. J. (1977). The biology of aging: 1976, an overview. Journal of the American Geriatrics Society, 25(3), 104111. https://doi.org/10.1111/j.1532-5415.1977.tb00271.x PMID:839041

United Nations Development Programme (UNDP). (2019). Human Development Report 2019. Beyond income, beyond averages, beyond today: Inequalities in human development in the 21st century. New York. http://hdr.undp.org/en/content/humandevelopment-report-2019" 